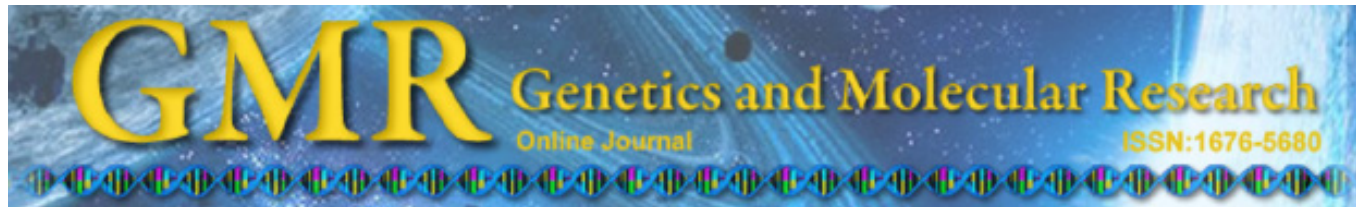

\title{
Clinical and genetic characterization of complete androgen insensitivity syndrome in a Chinese family
}

\author{
B.K. Li, Q. Ding, X.D. Wan and X. Wang \\ Department of Urology, Huashan Hospital, Fudan University, \\ Shanghai, China \\ Corresponding author: X. Wang \\ E-mail: seanw@medmail.com.cn / xiangwang111@163.com
}

Genet. Mol. Res. 10 (2): 1022-1031 (2011)

Received October 29, 2010

Accepted December 9, 2010

Published May 31, 2011

DOI 10.4238/vol10-2gmr1130

\begin{abstract}
We studied a family with two cousins who were diagnosed with complete androgen insensitivity syndrome, an X-linked disorder caused by mutations in the androgen receptor gene. A pedigree analysis and a molecular study using PCR and DNA sequencing clarified each female family member's androgen receptor status and revealed a mutation consisting of the deletion of exon 2 and surrounding introns of the androgen receptor gene. Based on the relative nucleotide positions, we concluded that the deletion mutation in exon 2 and its surrounding introns was approximately 6000 to $7000 \mathrm{bp}$. This mutation, never previously fully characterized using DNA sequencing, was responsible for complete androgen insensitivity syndrome in this family. Pedigree analysis with a molecular study of the androgen receptor gene in affected families facilitates genetic counseling provided to family members.
\end{abstract}

Key words: CAIS; Phenotype; Deletion mutation; AR gene 


\section{INTRODUCTION}

Androgen insensitivity syndrome (AIS) is an X-linked disorder characterized by endorgan resistance to testosterone and dihydrotestosterone (DHT). It typically results from mutations in the androgen receptor (AR) gene in patients with typical male 46,XY karyotypes. A wide spectrum of presentations has been noted, ranging from complaints of male infertility or under-masculinization characteristic of mild AIS to complete AIS (CAIS) (formerly called testicular feminization syndrome) in phenotypic females. Patients with CAIS have normal appearing female external genitalia and breast development, but present a lack of pubic hair and developmentally immature testes present in the labia majora, inguinal ring or intrabdominally. Demonstration of a genetic mutation in the AR gene, located on Xq11-12, has become the gold standard for verifying a diagnosis of CAIS (Nitsche and Hiort, 2000; Brinkmann, 2001; Oakes et al., 2008).

The AR is an intracellular transcription factor that binds to androgen as a hormone receptor complex. It is comprised of 4 functional domains: an N-terminal domain, encoded by exon 1; a DNA-binding domain, encoded by exons 2 and 3; a "hinge" region, encoded by exon 4, and an androgen-binding domain, encoded by exons 4-8 (McPhaul et al., 1993; Quigley et al., 1995; Melo et al., 2003; Jaaskelainen et al., 2006). Over 400 mutations, mostly point mutations, of the AR gene have been reported (Gottlieb et al., 2004). These mutations include: a) single point mutations resulting in amino acid substitution or a premature stop codon; b) nucleotide insertions or deletions that most often lead to a frame shift and premature termination; c) complete or partial gene deletions ( $>10$ nucleotides), and d) intronic mutations in either splice donor or acceptor sites, which affect the splicing of the AR RNA (McPhaul et al., 1993; Brinkmann, 2001).

We report our experience in treating two cousins with CAIS at Huashan Hospital of Fudan University. Diagnoses were made by physical examinations, B-ultrasounds and laboratory tests (including measurements of hormone levels and karyotype analysis). Polymerase chain reaction (PCR) and DNA sequencing were performed on leukocytes from the probands, obligate carriers, and female family members for the purpose of fully characterizing the AR gene mutation in this family and informing each female family member regarding her genetic status. The DNA mutation in the AR gene that was the cause of CAIS in this family, although previously reported in the AR mutation database (http://www.mcgill.ca/androgendb) (Gottlieb et al., 2004), has not yet been fully characterized. We also showed that our quick PCR exon analysis method can be easily adapted to genetic counseling for CAIS families.

\section{MATERIAL AND METHODS}

\section{Clinical subjects}

This study was approved by the institutional review board of Huashan Hospital, Fudan University. The present CAIS family first sought medical attention when a 24-year-old member with female social gender visited our hospital due to primary amenorrhea and who was later diagnosed with CAIS. The karyotype was 46,XY. Physical examination revealed normal breast development, vellus hair in the axilla and on the arms and legs, but absence of pubic hair, and a $4-\mathrm{cm}$ deep blind-ending vagina. B-ultrasound showed a testis and hernia in 
the right inguinal region. The uterus and Fallopian tubes could not be discerned by B-ultrasound. The patient expressed satisfaction with her sexual life. The karyotype analysis revealed $46, X Y$ chromosome complement. With a clinical diagnosis of CAIS, the patient underwent bilateral orchidectomy without vaginal lengthening. Testicular histology showed developmental immaturity of seminiferous tubules containing monolayers of Sertoli cells without spermatogenic cells or spermatozoa. A surgical specimen also showed hyperplasia of mesenchymal cells and fibrous tissue. Hormone replacement was administered consisting of $0.3 \mathrm{mg} / \mathrm{day}$ diethylstilbestrol (DES) for 21 days/month; the use of DES has been approved in China (Tian et al., 2005).

A second proband diagnosed with CAIS was a 22-year-old cousin with female social gender who also visited our hospital due to primary amenorrhea. The presentation, diagnosis, and treatment were the same as that of the cousin, except that testes were found in both inguinal regions. The karyotype was $46, \mathrm{XY}$.

\section{Pedigree analysis with molecular study}

A pedigree analysis of the family was performed (Figure 1). The probands were subjects III-B and III-H. Subject I-B and subject II-C, both deceased, were reportedly tall, infertile with female phenotypes and were suspected to have CAIS.

Genomic DNA was extracted from leukocytes of the CAIS patients, an obligate carrier, and normal females in the family using a Qiagen Pure Gene Blood Core Kit C according to manufacturer instructions (QIAGEN, Shanghai, China). Genomic DNA samples were subjected to PCR for the AR gene. A Primer Express ${ }^{\circledR}$ software v5.0 kit (Applied Biosystems, Foster City, CA, USA) was used to design PCR primers and to assure their specificities. Based on the adjacent intron sequences of the human AR gene (GenBank ID NC000023.10), the exon-containing PCR primers were designed. AR coding regions and adjacent introns of exons 2-8 and non-coding regions of exon 1 were screened using 8 sets of primers, which are listed in Table 1. An additional set of primers was designed to locate the positions of deletions in exon 2; these are shown in Table 2.

\begin{tabular}{|c|c|c|c|}
\hline Exon & Primer sequence & Location on chromosome X (start-end) & Length of amplicon (bp) \\
\hline \multirow[t]{2}{*}{ AR1-E1 } & Forward: 5'-ACCCGACTCGCAAACTGTTG & $66763824-66763843$ & 2879 \\
\hline & Reverse: 5'-TCTGAGTGTTCGCGCAGGTAG & $66766682-66766702$ & \\
\hline \multirow[t]{2}{*}{ AR1-E2 } & Forward: 5'-CTGCCATTCAGTGACATGTGTTG & $66863051-66863073$ & 279 \\
\hline & Reverse: 5'-CTGGGCCCTGAAAGGTTAGTG & $66863309-66863329$ & \\
\hline \multirow[t]{2}{*}{ AR1-E3 } & Forward: 5'-CTCATGGGCATTTCTGACTTTTG & $66905530-66905552$ & 586 \\
\hline & Reverse: 5'-TTGCCTATGAAAGGGTCAGCC & $66906095-66906115$ & \\
\hline \multirow{2}{*}{ AR1-E4 } & Forward: 5'-TCTGTGACCAGGGAGAATGGTG & $66931127-66931148$ & 528 \\
\hline & Reverse: 5'-GGGTTATGATGAAGACTGCCTGAG & $66931631-66931654$ & \\
\hline \multirow[t]{2}{*}{ AR1-E5 } & Forward: 5'-CTTAATGGCCAGCCTGGATG & $66937180-66937199$ & 437 \\
\hline & Reverse: 5'-CGCCTCATACTGGATTGGCTG & $66937596-66937616$ & \\
\hline \multirow[t]{2}{*}{ AR1-E6 } & Forward: 5'-GGCAATCAGAGACATTCCCTCTG & $66941598-66941620$ & 236 \\
\hline & Reverse: 5'-GGCATTCCCTGCACTTCTAGG & $66941813-66941833$ & \\
\hline \multirow[t]{2}{*}{ AR1-E7 } & Forward: 5'-GTGCTTTGTCTAATGCTCCTTCG & $66942603-66942625$ & 314 \\
\hline & Reverse: 5'-AACAGGTGGTGCCAGACTCTAGAG & $66942893-66942916$ & \\
\hline \multirow[t]{2}{*}{ AR1-E8 } & Forward: 5'-TCAGAGGTTGGGGAAGAGGCTAG & $66943451-66943473$ & 860 \\
\hline & Reverse: 5'-AATCAGTAACTCCCCATGGGCC. & $66944289-66944310$ & \\
\hline
\end{tabular}

The primer design and the locations of exons on chromosome X refer to NC_000023. 


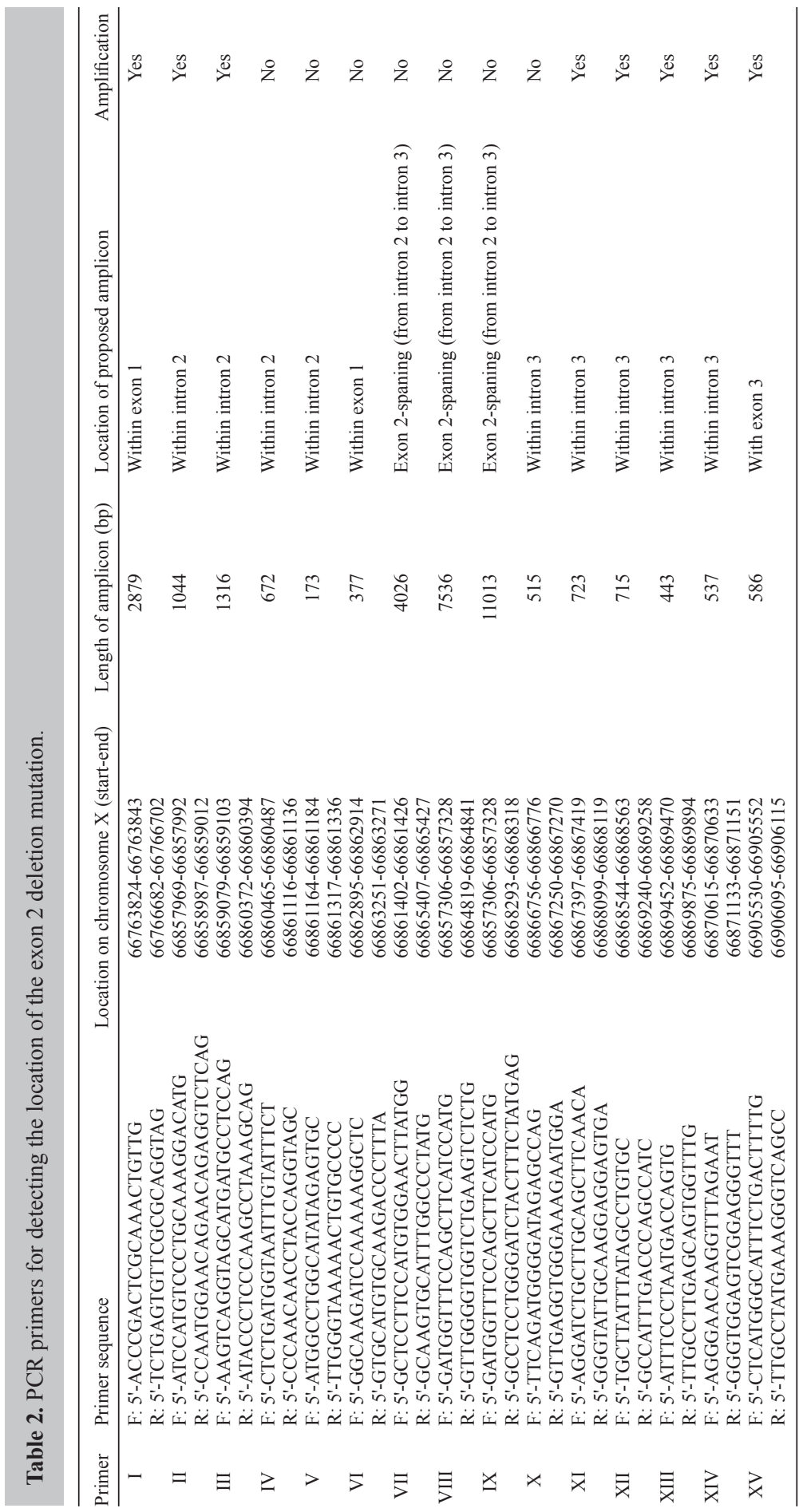




\section{Polymerase chain reaction}

According to the instructions for the HotStar Taq DNA PCR system (QIAGEN), PCRs were performed with a total volume of $50 \mu \mathrm{L}$ that contained $1 \mu \mathrm{g}$ genomic DNA, 200 $\mu \mathrm{M}$ of each dNTP, $0.25 \mu \mathrm{M}$ of each primer, $2 \mathrm{mM} \mathrm{MgCl}, 1.25 \mathrm{U}$ Hotstar Taq enzyme, and $5 \mu \mathrm{L}$ 10X PCR buffer. Reactions were performed in a thermal cycler (PTC-200, Bio-Rad, Hercules, CA, USA) with the following conditions: $94^{\circ} \mathrm{C}$ denaturation for $15 \mathrm{~min}, 94^{\circ} \mathrm{C}$ denaturation for $30 \mathrm{~s}, 55^{\circ} \mathrm{C}$ annealing for $30 \mathrm{~s}, 72^{\circ} \mathrm{C}$ extension for $45 \mathrm{~s}$, for a total of 32 cycles, followed by $72^{\circ} \mathrm{C}$ extension for $10 \mathrm{~min}$. All PCRs were performed in duplicate. A negative control (no DNA) was included in the PCR analysis to rule out carryover contamination. An amplicon $(10 \mu \mathrm{L})$ was subjected to gel electrophoresis. The remaining $40 \mu \mathrm{L}$ was further purified using a DNA fragment purification kit B (BioDev Tech, China) pending DNA sequencing. The DNA sequencing was carried out using an ABI 3730 xl DNA analyzer (Applied Biosystems).

\section{Quantitative real-time PCR (Q-PCR)}

Genomic DNA $(1 \mu \mathrm{g})$ extracted from a CAIS patient (III-B), an obligate carrier (IIB), and a normal female family member was subjected to amplification of the exon 2 containing the fragment using Q-PCR. Q-PCR was performed on an ABI 7500 fast real-time PCR system using the All-in-One ${ }^{\mathrm{TM}}$ Q-PCR Detection Kit (GeneCopoeia, USA) along with the AR1-E2 primers. For real-time PCR, the reaction was initiated at $95^{\circ} \mathrm{C}$ for 3 min for initial template denaturation, followed by a cycling protocol $\left(95^{\circ} \mathrm{C}\right.$ for $15 \mathrm{~s}, 60^{\circ} \mathrm{C}$ for $15 \mathrm{~s}$, and $72^{\circ} \mathrm{C}$ for $20 \mathrm{~s}$ ) for 30 cycles, and a final elongation $\left(72^{\circ} \mathrm{C}\right.$ for $\left.1 \mathrm{~min}\right)$. After the final cycle, melt curve analysis was performed to confirm amplification specificity. PCR signals were analyzed using the delta-delta $\mathrm{Ct}$ method with glyceraldehyde 3-phosphate dehydrogenase (GAPDH) as the internal control.

\section{RESULTS}

\section{Probands' clinical characteristics}

Figure 1 shows the pedigree analysis for this family with CAIS, including the two probands in this study (III-B and III-H). Table 3 shows the results of the hormone analyses for these probands (normal ranges are given for adult males). Other clinical presentations for the probands are given in Material and Methods (Clinical subjects).

\section{PCR results}

PCR amplification and sequencing of AR gene exons in the probands showed a deletion of exon 2 and its surrounding introns in the AR gene with a total of 6000-7000 bp missing. We used the human AR gene for comparisons (GenBank ID NC000023.10). Agarose gel electrophoresis imaging of PCR amplification of the AR gene exon 2 showed that PCR of genomic DNA from the CIAS patients produced no amplifications, indicat- 
ing exon deletions. The result of an obligate carrier (II-B) showed amplification of the AR exon 2, but with less intensity than that of controls (Figure 2A). The PCR analysis indicated that exons 3 to 5 of the AR gene, but not exon 2, could be detected for the CAIS patient (III-B) (Figure 2B). AR gene deletions in the probands were located somewhere between 66860369 and 66867397 of chromosome X. Table 2 shows the primers used for detecting deletion mutations within exon 2 . We used these primers to pinpoint the location of the exon 2 deletion mutation. The $5^{\prime}$ end nucleotide of reverse primer III is 66860369; the $3^{\prime}$ end nucleotide of forward primer XI is $66867397.66867397-66860369=7028$. Thus, the exon 2 deletion is about $7028 \mathrm{bp}$. We designed several primers to amplify DNA fragments between 66860369 and 66867397 , but no PCR products were amplified for the CAIS patients.

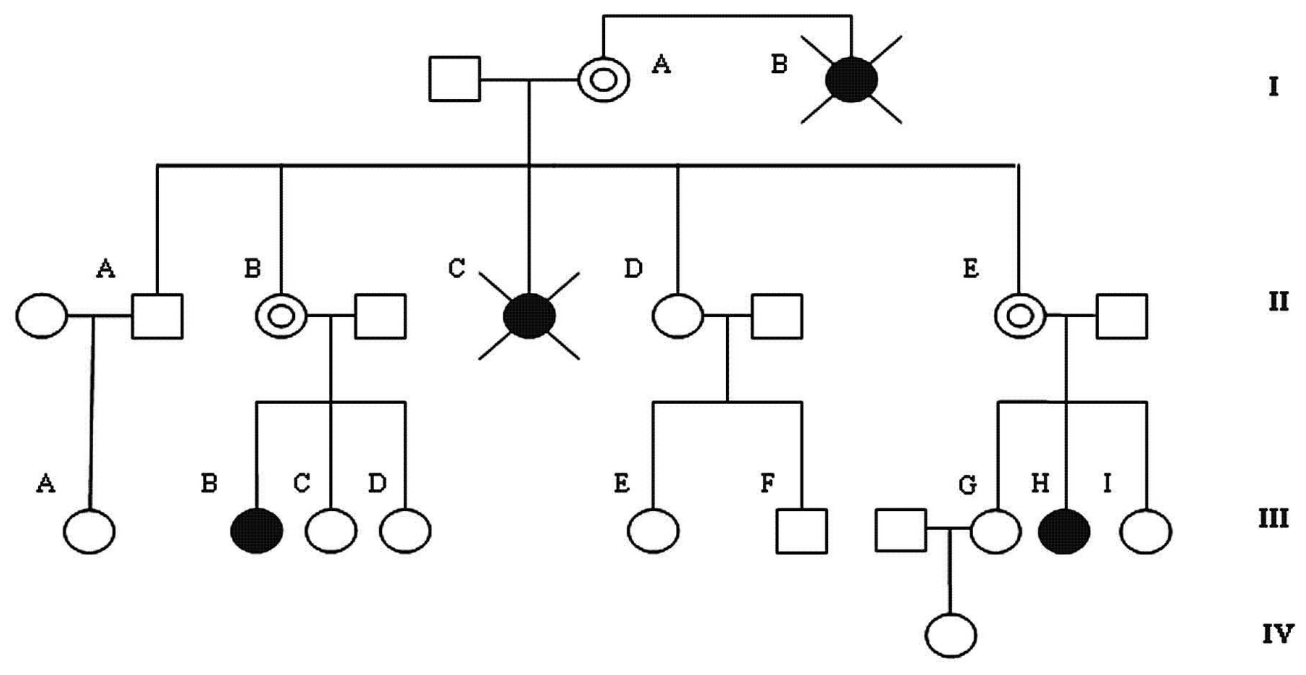

Figure 1. The pedigree of the family with complete androgen insensitivity syndrome (CAIS). Black circles $=$ CAIS 46, $\mathrm{XY}$ individuals; open circles $=$ normal females; open squares $=$ normal males; double open circles $=$ obligate carrier women; crossed black circles $=$ deceased individuals suspected of having CAIS.

Table 3. Hormone analysis results.

\begin{tabular}{lccc}
\hline & Normal male range & Patient III-B & Patient III-H \\
\hline Testosterone & $9.90-27.80 \mathrm{nM}$ & $23.5 \mathrm{nM}$ & $31.1 \mathrm{nM}$ \\
Estradiol & $28.00-156 \mathrm{pM}$ & $171.8 \mathrm{pM}$ & $143.3 \mathrm{pM}$ \\
Luteinizing hormone & $1.70-8.60 \mathrm{IU} / \mathrm{L}$ & $45.81 \mathrm{IU} / \mathrm{L}$ & $33.7 \mathrm{IU} / \mathrm{L}$ \\
Follicle-stimulating hormone & $1.50-12.40 \mathrm{IU} / \mathrm{L}$ & $2.35 \mathrm{IU} / \mathrm{L}$ & $13.8 \mathrm{IU} / \mathrm{L}$ \\
Dihydrotestosterone & $55.10-386.5 \mathrm{ng} / \mathrm{dL}$ & $51.0 \mathrm{ng} / \mathrm{dL}$ & $49.1 \mathrm{ng} / \mathrm{dL}$ \\
\hline
\end{tabular}



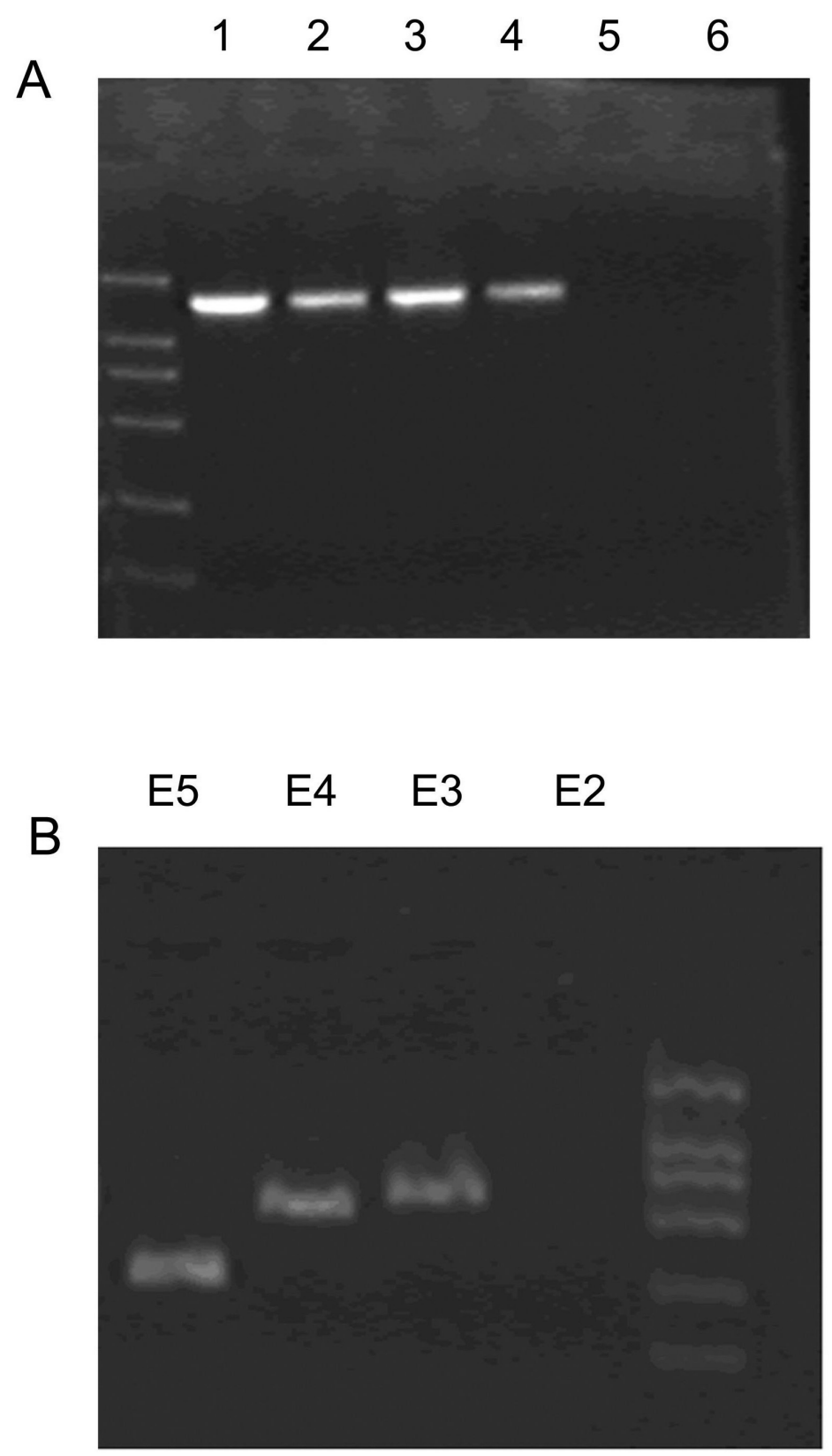

Figure 2. PCR amplification of the AR gene. A. Amplification of the AR gene exon 2 in family members. Lanes 1 to $3=$ Strong amplification in three normal family members. Notably, lane 2 is a normal male family member. Lane $4=$ Intermediate amplification in an obligate carrier mother of a CAIS patient (II-B). Lanes 5 and $6=$ No amplification in the CAIS patients (III-B and III-H). A DL2000 ${ }^{\mathrm{TM}}$ DNA Marker kit (TaKaRa, Japan) was used for the molecular weight markers, and the sizes of bands were 2000, 1000, 750, 500, 250, and $100 \mathrm{bp}$. B. Amplification of the AR gene exons 2 to 5 (E2-E5) in a CAIS patient (III-B). 
DNA sequencing confirmed that there was no point mutation, except the deletion of exon 2, and showed that the remaining exons and introns were intact in the AR genes of the probands.

None of the females in the pedigree in generations III and IV, except for the probands, were found to have CAIS or to be carriers. I-A, II-B and I-E were confirmed to be carriers. The origin of the mutation in this family appeared to be from the predecessors of I-A.

\section{Real-time PCR results}

Compared to the normal female family member, the exon 2 fragment expression signal of the obligate carrier (II-B) was 0.55864. GAPDH, but not the AR exon 2, was detected in the CAIS patient (III-B). The Ct values of all GAPDH reactions ranged from 22.09 to 22.84, suggesting that equal amounts of genomic DNA had been applied. Consistent with the results of conventional PCR, the Q-PCR results suggested that II-B, the mother of the CAIS patient, was an obligate carrier.

\section{DISCUSSION}

Few studies of CAIS have shown clinical and hormonal data combined with pedigree analysis and direct DNA sequencing to identify an AR gene mutation, as we have presented in this report. In addition, very few previous reports of exon 2 deletions can be found in the AR mutation database (http://www.mcgill.ca/androgendb). Another important aspect of our study is that it shows that family studies can be easily undertaken to provide members with the information they need for family planning, which has become an increasing concern for families with AR gene mutations and members with CAIS (Fogu et al., 2003; Cheikhelard et al., 2008).

The molecular basis of CAIS in this family was a deletion of exon 2 of the AR gene, as shown in the CAIS patients by failure of PCR amplification of exon 2. Gel electrophoresis imaging of PCR amplification of the AR gene exon 2 showed that the mother of subject III-B was the obligate carrier. The deletion was not found in the normal subjects of this family.

To the best of our knowledge, only three previous reports have described androgen resistance involving deletions in exon 2 of the AR gene. Avila et al. (2002) screened 27 patients and found 2 involving exon 2 deletions, although it was unclear whether these 2 patients were related to one another. Beitel et al. (1994) and Ahmed et al. (2000) both reported cases in which only a few nucleotides were deleted within exon 2 . These reports suggested the possibility of major structural changes in exon 2. Other reports have also suggested that major structural alterations in exons other than exon 2 might lead to androgen resistance (RisStalpers et al., 1994; MacLean et al., 2006).

Normal male sexual development requires both the synthesis of testosterone and DHT by the testes and the ability to form an active complex between AR protein and circulating androgens (Wilson et al., 2002). AIS, with an incidence of about 1 in 20,000, is an X-linked disorder caused by mutations in the AR gene (Hashmi et al., 2008). It is thought to be related to approximately $6-10 \%$ of cases of primary amenorrhea (Ross, 1985). Individuals with AIS are androgen resistant and have disorders of male sexual differentiation ranging from CAIS, with a normal female phenotype in the presence of an XY genotype, to phenotypic males who present infertility problems. Partial AIS presents ambiguous genitalia in patients with an XY 
karyotype (Alvarez et al., 2005). Individuals affected by CAIS may present a short, blind-ending vagina, the absence of Wolffian duct-derived structures, such as the epididymis, vas deferens and seminal vesicles, and the absence of a prostate gland. Breast development is observed at puberty, but pubic and axillary hairs are absent (Quigley et al., 1995). Müllerian structures are rarely seen in CAIS individuals (Ulloa-Aguirre et al., 1990). Gonadectomy may be indicated post-puberty because of the high incidence of testicular neoplasms in undescended testicles. However, as noted by Cools et al. (2009) the risk of germ cell tumors in CAIS patients is extremely low, and a more conservative approach to gonadectomy may be recommended.

Hormone replacement therapy is determined by serum hormone levels, which usually reveals an elevated testosterone in the setting of high luteinizing hormone (LH) (Oakes et al., 2008), as was observed in the probands in our case. As also noted, these probands had low DHT production, which is unusual for CAIS patients. This may be due to: 1) down-regulated LH receptors on Leydin cells in the testes resulting from chronic elevation of LH; 2) LH insensitivity syndrome, or 3) testicular atrophy.

The molecular basis of AIS is associated with a wide range of molecular defects that may or may not affect androgen binding. Genetic point mutations, which inhibit either DNA or hormone binding, are the most common genetic abnormalities (Brinkmann, 2001). According to the AR mutation database (http://www.mcgill.ca/androgendb), more than 400 different mutations, including deletions of exon 2, have so far been reported in the AR gene, and the number continues to increase. Most mutations observed in CAIS patients abolish either ligand or DNA binding activity, therefore AR exhibits no transactivation function (MacLean et al., 2004). The complexity of the phenotypic presentations of AIS, with genotype-phenotype variability, complicates both the diagnostic procedure and genetic counseling of affected families (Quigley et al., 2004).

Genetic testing empowered family members to realize that no one in generations III and IV of the family, other than the probands, was affected or was a carrier. Thus, our methods could be readily adapted to prenatal screening and genetic counseling for families harboring this rare disorder.

\section{ACKNOWLEDGMENTS}

Research supported by the Shanghai Rising-Star Program. We thank Dr. XuanChun Wang (Attending Doctor in the Department of Endocrinology, Hua Shan Hospital, Fudan University) and Professor Yuanfang Zhang (Professor in the Department of Urology, Hua Shan Hospital, Fudan University) for their valuable input during the study.

\section{REFERENCES}

Ahmed SF, Cheng A, Dovey L, Hawkins JR, et al. (2000). Phenotypic features, androgen receptor binding, and mutational analysis in 278 clinical cases reported as androgen insensitivity syndrome. J. Clin. Endocrinol. Metab. 85: 658-665.

Alvarez NR, Lee TM and Solorzano CC (2005). Complete androgen insensitivity syndrome: the role of the endocrine surgeon. Am. Surg. 71: 241-243.

Avila DM, Wilson CM, Nandi N, Griffin JE, et al. (2002). Immunoreactive AR and genetic alterations in subjects with androgen resistance and undetectable $\mathrm{AR}$ levels in genital skin fibroblast ligand-binding assays. J. Clin. Endocrinol. Metab. 87: 182-188.

Beitel LK, Prior L, Vasiliou DM, Gottlieb B, et al. (1994). Complete androgen insensitivity due to mutations in the 
probable alpha-helical segments of the DNA-binding domain in the human androgen receptor. Hum. Mol. Genet. 3: 21-27.

Brinkmann AO (2001). Molecular basis of androgen insensitivity. Mol. Cell. Endocrinol. 179: 105-109.

Cheikhelard A, Morel Y, Thibaud E, Lortat-Jacob S, et al. (2008). Long-term followup and comparison between genotype and phenotype in 29 cases of complete androgen insensitivity syndrome. J. Urol. 180: 1496-1501.

Cools M, Looijenga LH, Wolffenbuttel KP and Drop SL (2009). Disorders of sex development: update on the genetic background, terminology and risk for the development of germ cell tumors. World J. Pediatr. 5: 93-102.

Fogu G, Bertini V, Dessole S, Bandiera P, et al. (2003). Identification of a mutant allele of the androgen receptor gene in a family with androgen insensitivity syndrome: detection of carriers and prenatal diagnosis. Arch. Gynecol. Obstet. 269: 25-29.

Gottlieb B, Beitel LK, Wu JH and Trifiro M (2004). The androgen receptor gene mutations database (ARDB): 2004 update. Hum. Mutat. 23: 527-533.

Hashmi A, Hanif F, Hanif SM, Abdullah FE, et al. (2008). Complete androgen insensitivity syndrome. J. Coll. Phys. Surg. Pak. 18: 442-444.

Jaaskelainen J, Mongan NP, Harland S and Hughes IA (2006). Five novel androgen receptor gene mutations associated with complete androgen insensitivity syndrome. Hum. Mutat. 27: 291.

MacLean HE, Ball EM, Rekaris G, Warne GL, et al. (2004). Novel androgen receptor gene mutations in Australian patients with complete androgen insensitivity syndrome. Hum. Mutat. 23: 287.

MacLean HE, Favaloro JM, Warne GL and Zajac JD (2006). Double-strand DNA break repair with replication slippage on two strands: a novel mechanism of deletion formation. Hum. Mutat. 27: 483-489.

McPhaul MJ, Marcelli M, Zoppi S, Griffin JE, et al. (1993). Genetic basis of endocrine disease. 4. The spectrum of mutations in the androgen receptor gene that causes androgen resistance. J. Clin. Endocrinol. Metab. 76: 17-23.

Melo KF, Mendonca BB, Billerbeck AE, Costa EM, et al. (2003). Clinical, hormonal, behavioral, and genetic characteristics of androgen insensitivity syndrome in a Brazilian cohort: five novel mutations in the androgen receptor gene. J. Clin. Endocrinol. Metab. 88: 3241-3250.

Nitsche EM and Hiort O (2000). The molecular basis of androgen insensitivity. Horm. Res. 54: 327-333.

Oakes MB, Eyvazzadeh AD, Quint E and Smith YR (2008). Complete androgen insensitivity syndrome--a review. $J$. Pediatr. Adolesc. Gynecol. 21: 305-310.

Quigley CA, De Bellis A, Marschke KB, el-Awady MK, et al. (1995). Androgen receptor defects: historical, clinical, and molecular perspectives. Endocr. Rev. 16: 271-321.

Quigley CA, Tan JA, He B, Zhou ZX, et al. (2004). Partial androgen insensitivity with phenotypic variation caused by androgen receptor mutations that disrupt activation function 2 and the $\mathrm{NH}(2)-$ and carboxyl-terminal interaction. Mech. Ageing Dev. 125: 683-695.

Ris-Stalpers C, Verleun-Mooijman MC, de Blaeij TJ, Degenhart HJ, et al. (1994). Differential splicing of human androgen receptor pre-mRNA in X-linked Reifenstein syndrome, because of a deletion involving a putative branch site. Am. J. Hum. Genet. 54: 609-617.

Ross GT (1985). Disorders of the Ovary and Female Reproductive Tract. 7th edn. In: William Textbook of Endocrinology (Wilson JD and Foster DW, eds.). Saunders WB, Philadelphia, 206-258.

Tian QJ, Dai ZQ, Yu W, Tian JP, et al. (2005). Study of bone mineral density in complete androgen insensitivity syndrome patients. Zhonghua Fu Chan Ke Za Zhi 40: 799-802.

Ulloa-Aguirre A, Carranza-Lira S, Mendez JP, Angeles A, et al. (1990). Incomplete regression of mullerian ducts in the androgen insensitivity syndrome. Fertil. Steril. 53: 1024-1028.

Wilson JD, Leihy MW, Shaw G and Renfree MB (2002). Androgen physiology: unsolved problems at the millennium. Mol. Cell. Endocrinol. 198: 1-5. 